\title{
Literature Review on the Mode of Community Governance
}

\author{
Wang Zhihui \\ Yunnan university of finance and economics \\ Kun Ming, China \\ 328608635@qq.com
}

\author{
Cui Yuan \\ Yunnan university of finance and economics, \\ Kun Ming, China \\ 1213293873@qq.com
}

\begin{abstract}
-community governance plays an important role in the social development, there were three typical modes in western countries: government-led mode, community autonomy mode and mixed mode. These three modes had well-established community management system, including complete law, convenient facilities, high-quality and professional services providers. International experience showed that the development of community governance mode corresponded to a country's fundamental political system. In contrast, Chinese community governance was still in the stage of exploration in both the urban and rural areas, most of community governance were the government-led mode. According to present situation, Chinese community governance still dominated by government. This literature review hackled the typical modes of community governance, considered that China should reform the community governance modes and change the powers allocation. Chinese government should improve the diversified co-governance system to promote the development of community autonomy governance.
\end{abstract}

Key words—communities; governance; mode

\section{I.Basic Theories of Community Governance}

\section{A. Basic Concepts of Communities}

Community was proposed by British scholar Maine H.S. in 1871.

In 1887, German sociologist Ferdinand Tennis elaborated community for the first time in his Society and community. He held that a community was a regional social community with similar common values and cultural characteristics. Community referred to a group that was formed within a certain specific region by the people who mutually realize the diversified goals.

Robert M. Parker, a sociologist at the American University of Chicago argued that a community was "an assemblage of the groups that occupy a more or less specified area". A community is not only an assemblage of people, but it is also the assemblage of the organizational systems".

In the 1930s, Fei Xiaotong translated the works of Ferdinand Tennis, and introduced the word "communities" into China. In 1984, he expressed a community as "a big collection that is formed by the assemblage of several social groups or social organizations in a certain areas that is mutually associated in living".

In his book New theories of community, Fang Ming pointed out that: "a community refers a social group or social organization that assembles within a certain geographical domain. It is a social entity that is based on a set of norms and system."
Most of the scholars generally agreed that a community referred to the social community, it was composed of concentrated in certain region within the scope of the people.

\section{$B$. An Overview of Community Governance}

The word "governance" originated from the ancient Latin or ancient Greek "steering", which means control, guide and manipulate. Governance is the exercise of authority within a certain scope. The global governance committee defined it as: governance was a collection of the multiple modes, for the management of the same affairs by the public or private individuals and institutions. Governance is a process that mediates the conflicts. Governance includes the right to compel people to abide by the formal charters and rules as well as various kinds of informal arrangements. All these must agreed and granted power by the people and institutions.

$\mathrm{Hu}$ Xiang approved that community governance does not only has the one entity of the government, community autonomy organizations, third party departments, private departments solved the mutually concerned public affairs on their own resources and advantages, they were mutually dependent and formed a cooperative partnership.

Based on the characteristics of "governance", Chen Binhui defined community governance as the activities in which government,community autonomy organizations, non-profit and non-government organizations govern the community and residents mutually. Community governance features the following characteristics: (1) the diversification of the community power entities. (2) diversification of the means and modes of the community governance. (3) the voluntary participation of the community governance. (4) the networking of the community governance.

\section{Practice of the Chinese and International Community Governance Modes}

\section{A.Practice of the International Urban Community Governance Mode}

Based on the different degrees of associations of the government and communities, international urban community governance has formed three typical modes:

- Government-led mode. Government and the communities are closely associated. Take Singapore as an example, the basic units of the social administration are the communities. Housing 
Development Board (HDB) was especially established which was responsible for the community administration from top to bottom. The leading members of the community organizations were not produced by civil elections, but were appointed or recommended by the parliament members in the voting sections they are in. Therefore, the residents rarely take the initiatives to participate in the community administration, leading to poor democratic concepts of the community residents. In

addition, various facilities of the resident committees were constructed with government investments. The government was responsible for over $90 \%$ of the community infrastructure construction cost and $50 \%$ of the daily operational cost. ${ }^{[1]}$

- Community autonomy mode. Richard Box called the community governance mode of the US as "citizencentered intellectual structure ". The roles of the institutions of public powers were just an auxiliary assistance. To various states, municipalities and townships of the federation have basically adopted the operational mode "government being responsible for planning and guidance and financial supports, while community organization are responsible for the concrete implementations". The specific affairs were handed to the community organizations and nongovernmental organizations. The residents can indirectly impact the community's public affairs through community elections or party elections, and they can also directly decide on the community's public policies.

- Mixed mode. In this mode, the government and community autonomy organization management community together and the sources of funds are diversified. For example, in Japan, On one hand, it was the official "regional center", as the administrative management institution of a certain region, its functions were unitary, its duties were clarified. The administrative management institution focused on the management of the local affairs and serviced for the local residents. On the other hand, it was the civil "Collaborative council of the residential areas", which was a mass autonomy organization of public affair administration. The residents voluntarily participate in them and conduct democratic administration. The autonomy organizations can coordinate, enhance and balance

the work in communities. ${ }^{[2]}$

\section{B.Practice of International Rural Community Governance Mode}

The governance mode of international rural communities correspond to their urban community governance:

The government-led Singapore, by 2010, through the promotion of the HDB housing plan for communities, the urbanization rate of Singapore had reached $100 \%$.

The US, in an autonomy type mode, the Villagers' Committee was the power institution of the rural autonomy with the decision-making rights and certain legislative powers. The community villagers were the entity of the community management, the village governance institution only needs to be responsible for all villagers. In some developed nations or federal states, rural community governance is also such a mode, such as in Britain, Germany and Finland.

As the typical representatives of the mixed mode, the entities of the Japanese rural community governance had tended to be diversified. The mode were participated by various kinds of civil and social organizations and citizens. In the duplicate interactions between the government and the citizens, the job divisions were clarified. The government provided supports of policies, technologies and funds. The community residents were responsible for daily affairs. Italy, France, and Korea also adopt this mode.

\section{Practice of Chinese Urban Community \\ Governance Mode}

The Chinese research on community governance mode is mainly conducted around the various kinds of typical modes.

"Shanghai mode" positioned the communities on the Sub-district level and formed the "Sub-district communities", which combined the community governance with the reform of the urban administration system featuring "two-level governments, three-level administration, and four-level networks". In this mode, the Street Agency was the main body, strengthened the administrative power and administrative efficiency in the level of street. ${ }^{[3]}$

"Shenyang mode" involved the handover to the communities the powers of community administrations, including the autonomy power, initial review power, and the supervision power. A Community Administration Committee was established, which was produced by the elections through voluntary voting, the committee replaced the original Sub-district Committees. It was responsible for the jobs of the community education, services, administration and supervision. Meanwhile, a Community Deliberation Commission formed by the community representatives, CPPC Committee members, eminent persons and residents, the commission also put forward suggestions for the community management. ${ }^{\text {[4] }}$

Shenzhen City introduced the market mechanism and formed an enterprise-led mode. The real estate management companies proposed the management tenet of "Providing property owners with zero-flaw services". Companies became a "universal"community server and administrators. The Sub-district Offices were liberated from the original affairs. [5] Shenzhen introduced professional service powers as the social workers. Currently, among the community service center teams, the proportion of professional social workers is no less than $50 \%$. Meanwhile Shenzhen pioneered the community funds, and a total of 16 community foundations or funds

had been established. ${ }^{[6]}$

Hanjiang Community of Wuhan City redefined communities, it based on a scale of 1000-3000 households, Hanjiang community defined the communities as the new communities between "smaller than the neighborhood, but bigger that the Sub-district offices". Original 227 Subdistrict Offices were adjusted into 112 new communities. This mode straighten out the relationship between the neighborhood and the communities, redefined the responsibilities of the various departments and 
communities organizations. Sub-district Offices returned the community fund disposal rights and the community asset management rights to the communities. ${ }^{[7]}$

Shangcheng District of Hangzhou City conducted creation of the community governance mode. It created the community CPC construction work, thoroughly sorted out the relationships among the community CPC Party Committee, the Sub-district Committee and the Public Service Station. Shangcheng District clarified their respective functions and reformed the system of social workers, regarding the payments of the social workers. Shangcheng District explored the establishment of the Status-of-wage system, also created a platform of communication network and entered a new era of "Internet+community livelihood services so as to solve the problems of the residents. Shangcheng District implemented a " $333+x$ " service system, which leaded by the CPC Party Committee Branch, government and

diversified entities. ${ }^{[8]}$

Recently, the community governance mode of Tongling has aroused broad concerns nationwide, its practice was: the Sub-district offices were abolished, the original sub-districts and communities were integrated into a big community. The community CPC Party Affairs Committee, Sub-district Committee and public service center (community services center ) are established. The personnel of the original offices are lowered to the communities, thus reduced the administrative layers and

the government administration. ${ }^{[9]}$

\section{The Practice of Chinese Rural Community Governance Mode}

The construction of Chinese rural communities is still at the exploration stage, and various kinds of modes have not taken shape. Xiang Jiquan divided the rural communities into five modes from the establishments and boundaries of the rural communities: (1)"one village one community", only one community was established in one

village. (2)"multiple communities for one village". (3)"One community for multiple villages". (4) "Concentrated establishment of communities", in which communities were set up in the newly planned residential quarters with concentrated dwellings of the farmers. (5)"Quarters are established in communities". In"one village one community", "quarters" were established with the villager groups or the natural villages as the units, in"multiple village and one community", quarters were established with the villages as units. A community service center was established for the community.

Various regions have conducted proactive explorations on the rural community autonomy:

- Elite (capable persons) autonomy governance mode. It was prevalent in the developed economies, where the elite's personal ability was outstanding, they had outstanding talents in terms of economic or social activities, the capable persons play a leading role in the rural affairs. However, due to the worship of the elite, people neglected the supervisions on their powers.
- Regulation autonomy mode.

Regulations were produced through the mass discussion and mass resolution. Within the current legal framework, it refined operational mechanism of the village affairs and provided democratic rights for farmers. The regulations supplemented the blind spots in the polices and laws. On one hand, this mode effectively curbed such problems as elections illegal campaigning and family sectarian forces. On the other hand, the mode had enriched the voting modes of the villagers. ${ }^{[10]}$

\section{III.SUMMARY}

In view of the history of the community governance mode and the transformation process, there were three modes: government-led, mixed and community autonomy. International experience showed that the development of community governance mode corresponded to a country's fundamental political system. Most of developed countries had wellestablished community management system, including complete law, convenient facilities, high-quality and professional services providers. Chinese community governance mode both in urban and rural were the combination of the government and communities. Some developed regions had conducted positive explorations on community autonomy. On the whole, it still needed a long course for Chinese community governance to develop from the mode to the community autonomy mode. China should reform community governance modes, change the powers allocation and bring into market resources. The government should improve the diversified co-governance governance system. It is also noteworthy that even in the European nations and the US with higher degrees of autonomy, the government strength has never been withdrawn, this is an alert to position the government role in Chinese community governance. In the process of community governance, the government departments should encourage the social and civil participation. But, the government should not discard its due responsibilities and release its powers without limitations. Meanwhile, the government should attach greater importance to the scientific and informational governance means. Government, community autonomy organizations, non-profit and non-government organizations all need participate the community governance and do their best to satisfy people's diversified demands.

\section{Acknowledgment}

I would like to express my gratitude to all those who helped me during the writing of this thesis.

My deepest gratitude goes first and foremost to Professor Wangzhihui, my supervisor, for her constant encouragement and guidance. She has walked me through all the st ages of the writing of this thesis. Without her consistent and illuminating instruction, this thesis could not have reached its present form.

My gratitude also extends to my family who have bee $n$ assisting, supporting and caring for me all of my life. 


\section{REFERENCES}

[1] Wang Yuqing: Comparative research of the domestic and overseas community governance modes, [D]. 2009, p 28. (In Chinese)

[2] Xie Shouhong, Xie Shuangxi . Comparisons and references of the overseas community management modes [J] Social scientist ,2004 (1) (In Chinese)

[3] Li le. Current status and the explorations of problems for the new era community governance modes in Shanghai [J]. Modern communities , 2003(1) (In Chinese)

[4] Niu Junbin . Research of the participations of community governance by the social organizations of Shenyang City [J]. Journal of Liaoning University, 2011 (In Chinese)

[5] Huang Anxin . Research on the creative new type community governance modes during the process of urbanization $[\mathrm{J}]$. Journal of Guangzhou Radio and TV University, 2011, 11(4):56 - 63 (In Chinese)

[6] Dong Xiu . Creations of the civil society, civil governance and urban community governance modes - analysis of the theories and practices of the governance mode based on the linkage between the social workers and volunteers in Shenzhen City $[\mathrm{J}]$. Journal of Hubei Administration Institute, 2009(1) (In Chinese)

[7] Chen Weidong. Transformations of the social administration system of the urban grass-roots level : the transformation of unit management mode into the community governance mode-the innovations of the construction goal mode of Jianghan District of Wuhan City and its feasibility research [J]. Theory Monthly, 2000(12) (In Chinese)

[8] Yu Yanyan . Innovation of the government service modes and the practices by the local governance-Survey on the compound service governance mode of Shangcheng District of Hangzhou City $[\mathrm{J}]$. Selected works of the achievements of Beijing Municipal philosophy and social science research. 2013 (2nd) : 3-11 (In Chinese)

[9] Xie Baofu. Tongling mode of urban community governance [J]. New Chongqing, 2015(1) (In Chinese)

[10] Ren Zhian. Exploration of the rural community governance mode with the two modes in rural Shaoxing area as the case studies [J]. Heilongjiang Social Science, 2007(6) (In Chinese) 